\title{
Out-of-pocket costs are on the rise for commonly prescribed neurologic medications
}

Brian C. Callaghan, MD, MS, Evan Reynolds, MS, Mousumi Banerjee, PhD, Kevin A. Kerber, MD, MS, Lesli E. Skolarus, MD, MS, Brandon Magliocco, MPH, Gregory J. Esper, MD, MBA, and James F. Burke, MD, MS Neurology ${ }^{\circledR}$ 2019;92:e2604-e2613. doi:10.1212/WNL.0000000000007564

\section{Abstract}

\section{Objective}

To determine out-of-pocket costs for neurologic medications in 5 common neurologic diseases.

\section{Methods}

Utilizing a large, privately insured, health care claims database from 2004 to 2016, we captured out-of-pocket medication costs for patients seen by outpatient neurologists with multiple sclerosis (MS), peripheral neuropathy, epilepsy, dementia, and Parkinson disease (PD). We compared out-of-pocket costs for those in high-deductible health plans compared to traditional plans and explored cumulative out-of-pocket costs over the first 2 years after diagnosis across conditions with high- (MS) and low/medium-cost (epilepsy) medications.

\section{Results}

The population consisted of 105,355 patients with MS, 314,530 with peripheral neuropathy, 281,073 with epilepsy, 120,720 with dementia, and 90,801 with PD. MS medications had the fastest rise in monthly out-of-pocket expenses (mean [SD] \$15 [\$23] in 2004, \$309 [\$593] in 2016) with minimal differences between medications. Out-of-pocket costs for brand name medications in the other conditions also rose considerably. Patients in high-deductible health plans incurred approximately twice the monthly out-of-pocket expense as compared to those not in these plans (\$661 [\$964] vs \$246 [\$472] in MS, \$40 [\$94] vs \$18 [\$46] in epilepsy in 2016). Cumulative 2 -year out-of-pocket costs rose almost linearly over time in MS $(\$ 2,238$ $[\$ 3,342])$ and epilepsy $(\$ 230[\$ 443])$.

\section{Conclusions}

Out-of-pocket costs for neurologic medications have increased considerably over the last 12 years, particularly for those in high-deductible health plans. Out-of-pocket costs vary widely both across and within conditions. To minimize patient financial burden, neurologists require access to precise cost information when making treatment decisions.

\author{
Correspondence \\ Dr. Callaghan \\ bcallagh@med.umich.edu
}

\section{RELATED ARTICLE}

Patient Page

Rising medication costs for patients with neurologic disorders

Page e2622

From the Health Services Research Program, Department of Neurology (B.C.C., K.A.K., L.E.S., J.F.B.), and the School of Public Health (E.R., M.B.), University of Michigan; Veterans Affairs Healthcare System (B.C.C., J.F.B.), Ann Arbor, Ml; American Academy of Neurology (B.M.), Minneapolis, MN; and Department of Neurology (G.J.E.), Emory University, Atlanta, GA.

Go to Neurology.org/N for full disclosures. Funding information and disclosures deemed relevant by the authors, if any, are provided at the end of the article. 


\section{Glossary}

ICD-9 = International Classification of Diseases-9; ICD-10 = International Classification of Diseases-10; MS = multiple sclerosis; PD = Parkinson disease; TCA = tricyclic antidepressant.

Medications prescribed by neurologists accounted for $\$ 5$ billion in Medicare Part D payments in 2013, which only trailed internal medicine and family practice among specialties. ${ }^{1}$ Similarly, the median Medicare payment per month was $\$ 141$ for neurologist-prescribed drugs, fifth highest of all specialties. As new medications become available, such as biologic therapies for migraines, these costs are likely to rise. At the same time, the proportion of patients in highdeductible health plans rapidly increased from $8 \%$ in 2009 to $29 \%$ in 2016, resulting in a higher proportion of costs being shifted to patients. ${ }^{2}$

Given the high costs of many neurologic medications and the increasing cost sharing by patients, the total cost burden carried by patients is likely increasing, yet the magnitude of this burden is not well-quantified. Out-of-pocket costs can impose important financial hardship on patients. For example, higher costs lead to frequent medical debt and forgoing food or other essentials in patients with cancer and diabetes. ${ }^{3,4}$ In addition to the direct financial burdens, increasing out-ofpocket costs likely result in lower medication adherence. ${ }^{5,6}$ Reflecting the importance of these costs, patients with multiple sclerosis (MS) state that out-of-pocket costs are more important to them than drug efficacy and side effects, ${ }^{7}$ and these costs have been demonstrated to be associated with decreased MS medication adherence. ${ }^{8-10}$

Despite their importance, little is known about out-of-pocket costs for neurologic medications. We aimed to determine medication out-of-pocket costs and total estimated costs for 5 neurologic conditions. We also investigated the effects of high-deductible health plans on out-of-pocket costs and the cumulative costs for 2 neurologic conditions.

\section{Methods}

\section{Population}

We utilized the de-identified Clinformatics Datamart (OptumInsight, Eden Prairie, MN) database, which contains detailed medical and pharmaceutical claims on more than 73 million individuals insured by United Healthcare from 2004 to 2016. We identified patients who had an outpatient visit with a neurologist linked to 1 of 5 neurologic diagnoses (primary and secondary ICD-9 and ICD-10 codes included) and had a neurologic medication prescribed within the following 12 months. Outpatient visits were determined using place of service and neurologist visit using provider taxonomy codes. We chose to investigate the top 5 neurologic diseases based on Medicare payments for neurologist-prescribed medications. ${ }^{1}$ Diagnoses were identified using ICD-9 and
ICD-10 codes; namely, MS (340, G35), peripheral neuropathy (356 [all inclusive], 357 [except 357.0, 357.81], G60, G62, G63, G652), epilepsy (345, G40), dementia (331 except for 331.3/4/5, G30, G31), and Parkinson disease (PD) (332, G20, G21). All those included had at least 1 neurologic medication corresponding to the diagnosis.

For simplicity, we investigated the top 5 most commonly prescribed medications by neurologists for each condition based on Medicare data. ${ }^{1}$ However, we also made several additions for known high-cost treatments that were not reflected by that simple rule: we included all Food and Drug Administration-approved MS medications (teriflunomide, peginterferon- $\beta-1 \mathrm{a}$, interferon- $\beta-1 \mathrm{~b}$, interferon- $\beta-1 \mathrm{a}$ [Rebif], interferon- $\beta$-1a $[$ Avonex $]$, glatiramer acetate, fingolimod, dimethyl fumarate), added lacosamide as a brand name epilepsy medication, and included venlafaxine as a peripheral neuropathy medication that transitioned from brand to generic.

\section{Demographics and clinical variables}

The database included information on patient age, sex, race/ ethnicity, geographic region, education level, household income, insurance plan type, high-deductible health plan status (categorical variable based on those with a health savings account or health reimbursement arrange), and Charlson comorbidity index. ${ }^{11}$

\section{Outcomes}

Mean out-of-pocket costs for a 30-day supply of a neurologic prescription was the primary outcome. This included the copay and deductible payments associated with the prescription. To calculate the mean out-of-pocket costs, we had to account for the fact that a single patient often had multiple prescriptions of the same medication in the year after initial diagnosis. Therefore, we first determined the patient-specific mean out-of-pocket cost. Then, for each medication, we calculated the population mean out-of-pocket cost by averaging the patient-specific values for each year from 2004 to 2016 . We only plotted costs when there were at least 50 patients who had a particular prescription in that given year in order to provide precise estimates. Mean estimated total costs for a 30-day supply was a secondary outcome and was calculated with the same methodology.

\section{Statistical analysis}

Descriptive statistics were used to characterize each of the 5 neurologic disease populations. We calculated the mean outof-pocket costs in those with and those without a highdeductible health plan in those with MS and epilepsy from 2006 to 2016 (earlier years contained few patients in highdeductible health plans). We chose these 2 conditions to 
highlight 1 disease with high-cost medications (MS) and 1 disease with low- and medium-cost medications (epilepsy). Similarly, to estimate the effect of medication costs for neurologic diseases over time and to compare these costs to a patient's overall prescription costs, we calculated the cumulative out-of-pocket costs in the 2 years following an incident diagnosis (no previous diagnosis in at least the previous 2 years) of MS or epilepsy in 2012-2013. Focusing on this time frame allowed us to investigate the most recent cumulative out-ofpocket costs for these 2 conditions. For each patient, we calculated the cumulative out-of-pocket costs for each day of the 2 years after the incident diagnosis. Then for each day after initial diagnosis, we determined the population mean cumulative outof-pocket cost for both disease-specific prescriptions and for all prescriptions. We also calculated the 5th, 10th, 25th, 50th, 75th, 90th, and 95th percentiles of out-of-pocket costs at 2 years for both conditions to better understand the variability in these costs. We also modeled cumulative out-of-pocket costs as a function of total medication cost, patient demographics, insurance plan type, high-deductible plan status, and Charlson score in patients with MS.

Data management and analysis was completed using SAS v 9.4 (SAS Institute, Cary, NC). Figures were created using the ggplot2 package in $\mathrm{R} v$ 3.4.2.

\section{Data availability}

The Clinformatics Datamart (OptumInsight, Eden Prairie, $\mathrm{MN}$ ) database is commercially available.

\section{Standard protocol approvals, registrations, and patient consents}

The University of Michigan institutional review board determined that this study was exempt.

\section{Results}

We identified 105,355 patients with MS, 314,530 with peripheral neuropathy, 281,073 with epilepsy, 120,720 with dementia, and 90,801 with PD. Demographics and clinical characteristics of these patient populations are provided in the table. MS and epilepsy patients are more likely to be younger and in high-deductible plans.

\section{Multiple sclerosis}

For the 8 MS medications, monthly out-of-pocket costs were similar when comparing the different medications, but these costs rose exponentially from 2004 to 2016 for all of them, starting at a mean (SD, 5th-95th percentile) of $\$ 15$ ( $\$ 23$, $\$ 10-\$ 67)$ in 2004 and rising to $\$ 309(\$ 593, \$ 0-\$ 1,460)$ by 2016 (figure 1A). The median (interquartile range) monthly out-of-pocket cost increased from \$14 (\$10-\$16) in 2004 to $\$ 59$ (\$32-\$301) in 2016. In 2016, 66.8\% of the mean out-ofpocket costs comprised copays and $33.2 \%$ deductibles. With the exception of interferon- $\beta$-1a, the total monthly costs (out-ofpocket plus insurance payment) were stable over time, particularly from 2013 to 2016, with a total monthly cost mean (SD, 5th-95th percentile) of $\$ 4,527$ ( $\$ 1,354, \$ 3,899-\$ 6,046)$ during that time. Monthly total costs of interferon- $\beta$-1a were comparable to other MS medications, with the exception of 2008-2012, when they were much higher.

\section{Peripheral neuropathy}

From 2004 to 2016, amitriptyline and nortriptyline, which had been generic for many years, had low monthly out-ofpocket and total costs throughout the study period (figure 1B). Gabapentin became generic around 2004, with total costs declining to similar levels as the tricyclic antidepressants (TCAs) after 10 years. In contrast, gabapentin's monthly out-of-pocket costs decreased to similar levels of the TCAs after 5 years. Pregabalin was only available as a brand medication with a sharp rise in monthly out-of-pocket costs from 2014 to 2016, but stable total costs. Venlafaxine monthly out-of-pocket and total costs declined to become similar to those of the TCAs after 5 years of becoming a generic medication. Duloxetine monthly out-of-pocket and total costs declined in the 3 years after becoming generic, but remained substantially more than other generic medications in this class. In 2016, monthly mean out-of-pocket costs were $\$ 66$ $(\$ 90, \$ 0-\$ 250)$ for pregabalin, $\$ 32(\$ 32, \$ 0-\$ 80)$ for duloxetine, $\$ 13(\$ 18, \$ 0-\$ 42)$ for tramadol, $\$ 12$ ( $\$ 20$, $\$ 0-\$ 36)$ for amitriptyline, $\$ 10(\$ 13, \$ 0-\$ 29)$ for venlafaxine, $\$ 8(\$ 12, \$ 0-\$ 20)$ for gabapentin, and $\$ 7(\$ 5, \$ 0-\$ 15)$ for nortriptyline.

\section{Epilepsy}

Since 2010, monthly out-of-pocket and total costs for topiramate, levetiracetam, lamotrigine, divalproic acid, and carbamazepine have remained stable, with the exception of rising out-of-pocket costs for carbamazepine between 2014 and 2016 (figure 1C). Lacosamide monthly total costs have remained steady since 2009, but out-of-pocket costs have steadily risen since 2010. In 2016, monthly out-of-pocket costs were $\$ 86(\$ 140, \$ 0-\$ 320)$ for lacosamide, $\$ 39$ (\$46, $\$ 0-\$ 124)$ for carbamazepine, $\$ 20(\$ 36, \$ 0-\$ 84)$ for divalproex sodium, $\$ 19(\$ 56, \$ 0-\$ 60)$ for lamotrigine, $\$ 12$ (\$30, $\$ 0-\$ 35)$ for levetiracetam, and $\$ 12(\$ 35, \$ 0-\$ 30)$ for topiramate.

\section{Dementia}

Monthly total costs remained stable for donepezil, memantine, rivastigmine, and galantamine with the exception of sharp declines in donepezil after 2010 and in memantine after 2014 when these medications became generic with concomitant drops in their out-of-pocket costs (figure 1D). Monthly out-of-pocket costs for rivastigmine and galantamine increased from 2014 to 2016. In 2016, monthly out-of-pocket costs were $\$ 99$ (\$97, \$0-\$338) for rivastigmine, $\$ 63$ (\$85, $\$ 0-\$ 192)$ for memantine, $\$ 59$ (\$57, \$1-\$180) for galantamine, and $\$ 4(\$ 7, \$ 0-\$ 12)$ for donepezil.

\section{Parkinson disease}

Total monthly costs of carbidopa-levodopa and amantadine remained low from 2004 to 2016. Ropinirole and pramipexole total costs dropped precipitously after 2007 and 2010, 
Table Demographic and clinical characteristics of the 5 neurologic patient groups

\begin{tabular}{|c|c|c|c|c|c|}
\hline $\begin{array}{l}\text { Demographics and } \\
\text { clinical variables }\end{array}$ & $\begin{array}{l}\text { Multiple sclerosis }(n= \\
105,355)\end{array}$ & $\begin{array}{l}\text { Peripheral neuropathy ( } \mathrm{n} \\
=314,530 \text { ) }\end{array}$ & $\begin{array}{l}\text { Epilepsy }(n= \\
281,073)\end{array}$ & $\begin{array}{l}\text { Parkinson disease }(\mathrm{n} \\
=90,801)\end{array}$ & $\begin{array}{l}\text { Dementia }(n= \\
120,720)\end{array}$ \\
\hline Age, y, mean (SD) & $46.2(12.4)$ & $60.6(15.6)$ & $38.8(22.6)$ & $70.9(10.8)$ & $72.4(13.0)$ \\
\hline \multicolumn{6}{|l|}{ Sex } \\
\hline Female & $79,279(75.3)$ & $167,974(53.4)$ & 151,545 (53.9) & $38,430(42.3)$ & $68,481(56.7)$ \\
\hline Missing & $1,088(1.3)$ & $2,963(0.9)$ & $2,508(0.9)$ & $789(0.9)$ & $906(0.8)$ \\
\hline \multicolumn{6}{|l|}{ Race/ethnicity } \\
\hline Asian & $1,306(1.2)$ & $6,045(1.9)$ & $6,983(2.5)$ & $2,132(2.4)$ & $2,406(2.0)$ \\
\hline Black & $8,848(8.4)$ & $32,150(10.2)$ & $26,404(9.4)$ & $5,855(6.5)$ & $11,279(9.3)$ \\
\hline Hispanic & $6,113(5.8)$ & $22,296(7.1)$ & $22,783(8.1)$ & $5,936(6.5)$ & $8,739(7.2)$ \\
\hline White & $73,777(70.0)$ & 219,793 (69.9) & $187,872(66.8)$ & $64,228(70.7)$ & $84,983(70.4)$ \\
\hline Unknown & $15,311(14.5)$ & $34,246(10.9)$ & $37,031(13.2)$ & $12,650(13.9)$ & $13,323(11.0)$ \\
\hline \multicolumn{6}{|l|}{ Geographic region } \\
\hline East North Central & $17,582(16.7)$ & $39,131(12.4)$ & $44,009(15.7)$ & $13,975(15.4)$ & $15,944(13.2)$ \\
\hline East South Central & $4,529(4.3)$ & $15,824(5.0)$ & $13,500(4.8)$ & $3,486(3.8)$ & $4,796(4.0)$ \\
\hline Middle Atlantic & $9,376(8.9)$ & $24,357(7.7)$ & $24,542(8.7)$ & $9,051(10.0)$ & $11,748(9.7)$ \\
\hline Mountain & $10,817(10.3)$ & $31,194(9.9)$ & $25,402(9.0)$ & $9,163(10.1)$ & $11,942(9.9)$ \\
\hline New England & $4,542(4.3)$ & $11,982(3.8)$ & $11,258(4.0)$ & $5,448(6.0)$ & $7,230(6.0)$ \\
\hline Pacific & $6,847(6.5)$ & $17,405(5.5)$ & $17,673(6.3)$ & $7,304(8.0)$ & $9,091(7.5)$ \\
\hline South Atlantic & $27,507(26.1)$ & $99,181(31.5)$ & $76,101(27.1)$ & $22,814(25.1)$ & $35,673(29.6)$ \\
\hline West North Central & $11,097(10.5)$ & $27,289(8.7)$ & $26,385(9.4)$ & $10,076(11.1)$ & $11,354(9.4)$ \\
\hline West South Central & $11,774(11.2)$ & $44,559(14.2)$ & $39,227(14.0)$ & $8,511(9.4)$ & $11,786(9.8)$ \\
\hline Missing & $1,284(1.2)$ & $3,608(1.1)$ & $2,976(1.1)$ & $973(1.0)$ & $1,156(1.0)$ \\
\hline \multicolumn{6}{|l|}{ Education level } \\
\hline Less than 12 th grade & $304(0.3)$ & $1,754(0.6)$ & $1,472(0.5)$ & $496(0.6)$ & $647(0.5)$ \\
\hline High school diploma & $24,464(23.2)$ & $91,572(29.1)$ & 75,588 (26.9) & $23,205(25.6)$ & $31,808(26.4)$ \\
\hline $\begin{array}{l}\text { Less than bachelor's } \\
\text { degree }\end{array}$ & $51,998(49.4)$ & $153,766(48.9)$ & $132,776(47.2)$ & $44,240(48.7)$ & $60,993(50.5)$ \\
\hline > Bachelor's degree & $16,934(16.1)$ & $42,640(13.6)$ & $43,292(15.4)$ & $12,950(14.3)$ & $17,346(14.4)$ \\
\hline Missing & $11,655(11.1)$ & 24,798 (7.9) & $28,007(10.0)$ & $9,910(10.9)$ & $9,926(8.2)$ \\
\hline \multicolumn{6}{|l|}{ Household income } \\
\hline$<\$ 40 K$ & $10,598(10.1)$ & $61,883(19.7)$ & $35,395(12.6)$ & $19,989(22.0)$ & $32,045(26.5)$ \\
\hline$\$ 40 K-\$ 49 K$ & $4,991(4.7)$ & $20,843(6.6)$ & $13,852(4.9)$ & $6,079(6.7)$ & $8,778(7.3)$ \\
\hline$\$ 50 \mathrm{~K}-\$ 59 \mathrm{~K}$ & $5,131(4.9)$ & $19,649(6.3)$ & $13,881(4.9)$ & $5,526(6.1)$ & $7,793(6.5)$ \\
\hline$\$ 60 \mathrm{~K}-\$ 74 \mathrm{~K}$ & $7,554(7.2)$ & $25,482(8.1)$ & $19,131(6.8)$ & $6,754(7.4)$ & $9,389(7.8)$ \\
\hline$\$ 75 K-\$ 99 K$ & $11,094(10.5)$ & $33,199(10.6)$ & $26,902(9.6)$ & $8,171(9.0)$ & $11,471(9.5)$ \\
\hline$\$ 100 \mathrm{~K}+$ & $26,159(24.8)$ & $65,169(20.7)$ & $62,621(22.3)$ & $13,999(15.4)$ & $18,800(15.6)$ \\
\hline Missing & $39,828(37.8)$ & $88,305(28.1)$ & $109,291(38.9)$ & $30,283(33.4)$ & $32,444(26.9)$ \\
\hline \multicolumn{6}{|l|}{ Insurance plan type } \\
\hline EPO & $8,540(8.1)$ & $18,890(6.0)$ & $24,007(8.5)$ & $2,221(2.5)$ & $3,150(2.6)$ \\
\hline
\end{tabular}


Table Demographic and clinical characteristics of the 5 neurologic patient groups (continued)

\begin{tabular}{|c|c|c|c|c|c|}
\hline $\begin{array}{l}\text { Demographics and } \\
\text { clinical variables }\end{array}$ & $\begin{array}{l}\text { Multiple sclerosis }(n= \\
105,355)\end{array}$ & $\begin{array}{l}\text { Peripheral neuropathy ( } \mathrm{n} \\
=314,530)\end{array}$ & $\begin{array}{l}\text { Epilepsy }(n= \\
281,073)\end{array}$ & $\begin{array}{l}\text { Parkinson disease ( } \\
=90,801)\end{array}$ & $\begin{array}{l}\text { Dementia }(n= \\
120,720)\end{array}$ \\
\hline нмо & $30,308(28.8)$ & $108,583(34.5)$ & $82,372(29.3)$ & $36,699(40.4)$ & 47,631 (39.5) \\
\hline IND & $513(0.5)$ & $7,229(2.3)$ & $2,143(0.8)$ & $4,008(4.4)$ & $5,166(4.3)$ \\
\hline POS & $42,541(40.4)$ & 85,929 (27.3) & $111,448(39.7)$ & $12,017(13.2)$ & 15,599 (12.9) \\
\hline PPO & $14,968(14.2)$ & $46,620(14.8)$ & $38,689(13.8)$ & $12,411(13.7)$ & $17,359(14.4)$ \\
\hline Other & 7,407 (7.0) & $44,386(14.1)$ & $19,959(7.1)$ & $22,667(25.0)$ & $30,924(25.6)$ \\
\hline Missing & $1,078(1.0)$ & $2,893(0.9)$ & $2,455(0.9)$ & $778(0.9)$ & $891(0.7)$ \\
\hline $\begin{array}{l}\text { High-deductible health } \\
\text { plan }\end{array}$ & $7,354(7.0)$ & $12,675(4.0)$ & $19,481(6.9)$ & $1,772(2.0)$ & $2,521(2.1)$ \\
\hline Missing & $1,078(1.0)$ & $2,893(0.9)$ & 2,455 (0.9) & 778 (0.9) & $891(0.7)$ \\
\hline Charlson score, mean (SD) & $0.4(0.9)$ & $1.5(1.7)$ & $0.7(1.3)$ & $1.2(1.7)$ & $1.8(1.9)$ \\
\hline
\end{tabular}

Abbreviations: $\mathrm{EPO}=$ Exclusive Provider Organization; HMO = Health Maintenance Organization; IND = Indemnity, POS = point of service; PPO = Preferred Provider Organization.

Values are $\mathrm{n}(\%)$ unless otherwise specified.

respectively, after they became generic. Monthly out-ofpocket costs for ropinirole and pramipexole dropped at the same time, but took 5-6 years to reach comparable levels with carbidopa-levodopa (figure 1E). Total costs for rasagiline remained stably high throughout the study with out-of-pocket costs rising from 2014 to 2016. Monthly out-of-pocket costs for pramipexole and amantadine also rose from 2014 to 2016. In 2016 , monthly out-of-pocket costs were $\$ 94$ (\$108, \$2-\$302) for rasagiline, $\$ 39$ ( $\$ 93, \$ 0-\$ 108)$ for amantadine, $\$ 36$ ( $\$ 47$, $\$ 0-\$ 143)$ for pramipexole, $\$ 12$ (\$24, $\$ 0-\$ 43)$ for ropinirole, and $\$ 6(\$ 9, \$ 0-\$ 20)$ for carbidopa-levodopa.

\section{High-deductible health plans}

For patients with MS in high-deductible health plans, monthly out-of-pocket costs were $\$ 661(\$ 964, \$ 0-\$ 2,631)$ in 2016 compared to $\$ 246(\$ 472, \$ 0-\$ 1,211)$ for those not in highdeductible health plans (figure 2, A and B). For epilepsy patients in high-deductible health plans, monthly out-ofpocket costs were $\$ 40(\$ 94, \$ 0-\$ 158)$ in 2016 compared to $\$ 18$ (\$46, \$0-\$58) in those not in high-deductible health plans (figure 2, C and $\mathrm{D}$ ).

\section{Cumulative costs}

For patients with MS, cumulative out-of-pocket costs were a mean of $\$ 2,238(\$ 3,342)$ in the 2 years after diagnosis, which accounted for $77.4 \%$ of their total cumulative medication outof-pocket costs (figure 3A). The 5th, 10th, 25th, 50th, 75th, 90th, and 95th percentiles of out-of-pocket costs at 2 years were $\$ 90, \$ 209, \$ 848, \$ 2,134, \$ 6,334$, and $\$ 9,855$, respectively. For epilepsy patients, cumulative out-of-pocket costs were $\$ 230$ (\$443) in the 2 years after diagnosis, which accounted for $21.7 \%$ of their total cumulative medication outof-pocket costs (figure 3B). The 5th, 10th, 25th, 50th, 75th, 90th, and 95th percentiles of out-of-pocket costs at 2 years were $\$ 5, \$ 10, \$ 105, \$ 234, \$ 510$, and $\$ 865$, respectively. For both patient populations, the rise in cumulative costs was almost linear.

In patients with MS, cumulative out-of-pocket costs were associated with total costs and high-deductible health plan status, but not insurance plan type.

\section{Discussion}

This is the first study to detail out-of-pocket costs related to neurologist care using nationally representative data from a large private health insurer. Focusing on 5 common neurologic conditions, we found that out-of-pocket costs are substantial, vary widely within and across conditions, and are rising particularly fast from 2014 to 2016. MS medications had the highest out-of-pocket costs and they are increasing exponentially. When a neurologist chooses to prescribe a medication, the difference in out-of-pocket costs can be considerable, especially when comparing brand to generic medications. Patients in high-deductible health plans are particularly vulnerable to high out-of-pocket costs, given that their costs are usually twice as high as those of patients in traditional plans. The cumulative out-of-pocket costs rise almost linearly over time, indicating that these costs remain important even 2 years after the diagnosis.

In 2004, out-of-pocket costs were of such low magnitude that physicians could typically ignore these costs for most patients and not adversely affect the financial status of patients or their adherence to medications. However, by 2016, out-of-pocket costs have risen to the point where neurologists should consider out-of-pocket costs for most medications and for most patients. With the exception of MS medications, changes in out-of-pocket costs mostly paralleled changes in total costs for 
Figure 1 Monthly out-of-pocket costs for 5 common neurologic diagnoses from 2004 to 2016

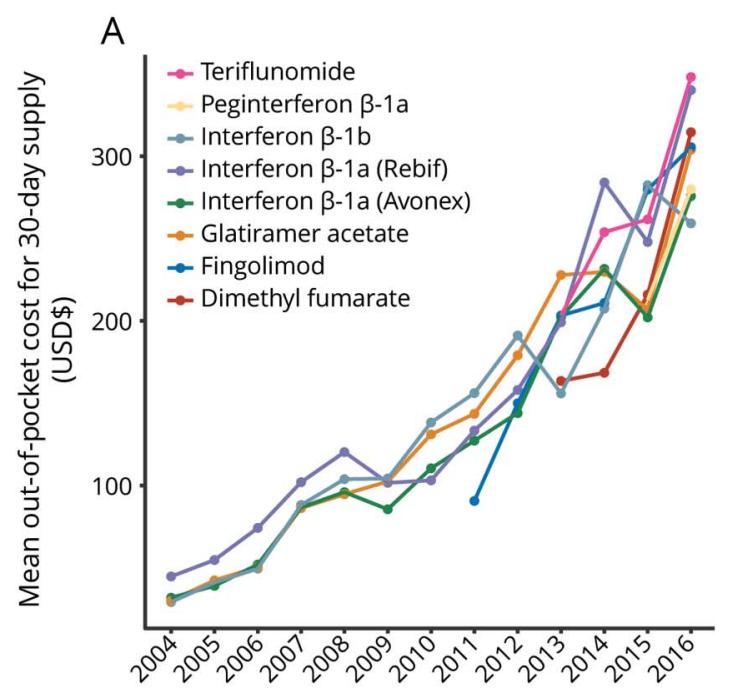

B

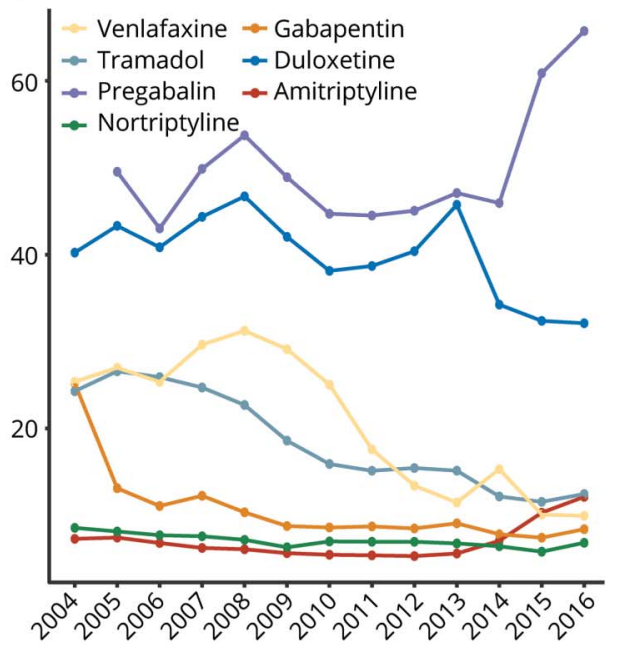

C

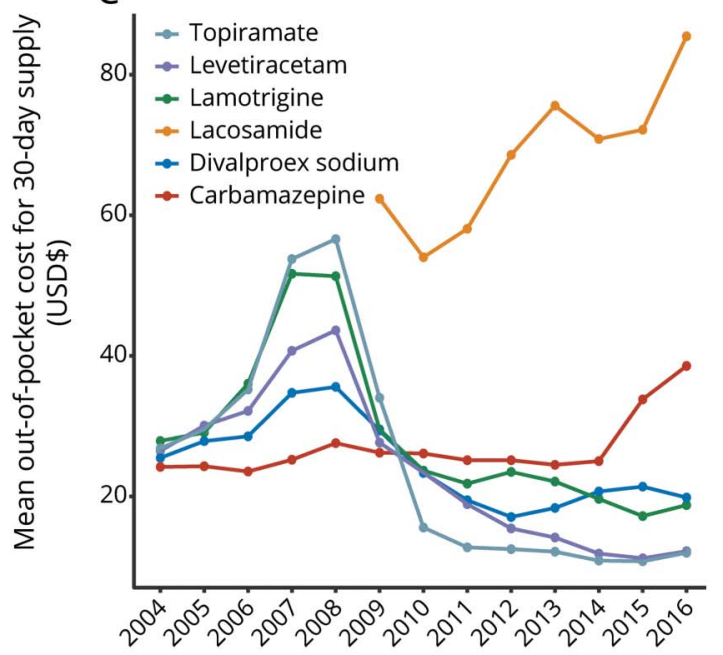

D

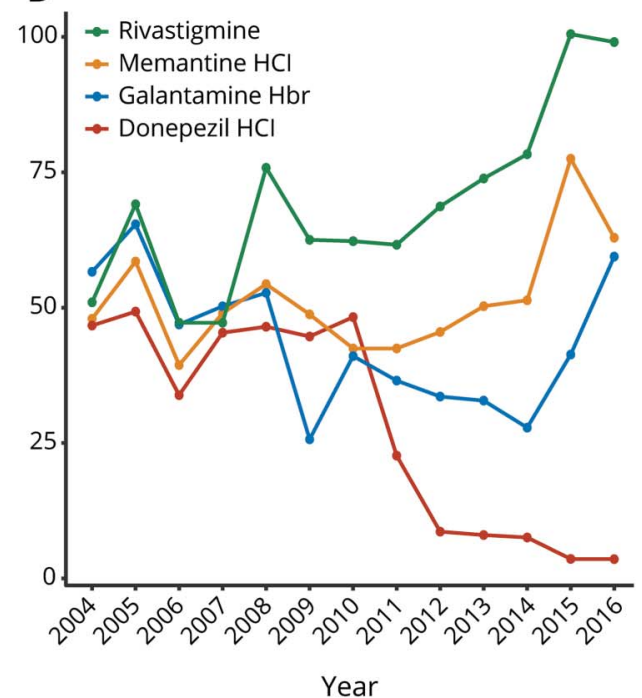

$\mathrm{E}$

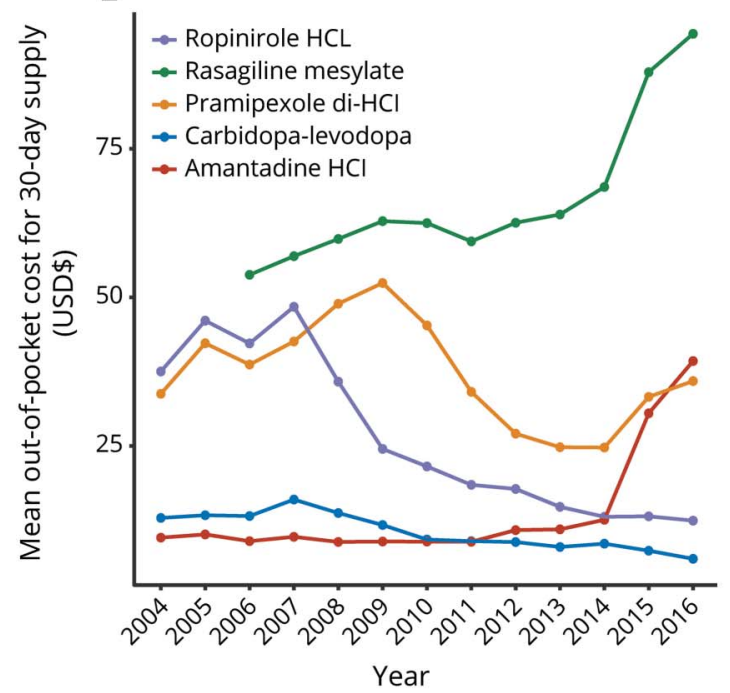

Year

Monthly out-of-pocket costs (copay and deductible costs) for medications prescribed within 12 months of an outpatient visit to a neurologist for patients with multiple sclerosis (A), peripheral neuropathy (B), epilepsy (C), dementia (D), and Parkinson disease (E). 
Figure 2 Monthly out-of-pocket costs for 2 common neurologic disorders in those with and without a high-deductible health plan from 2009 to 2016
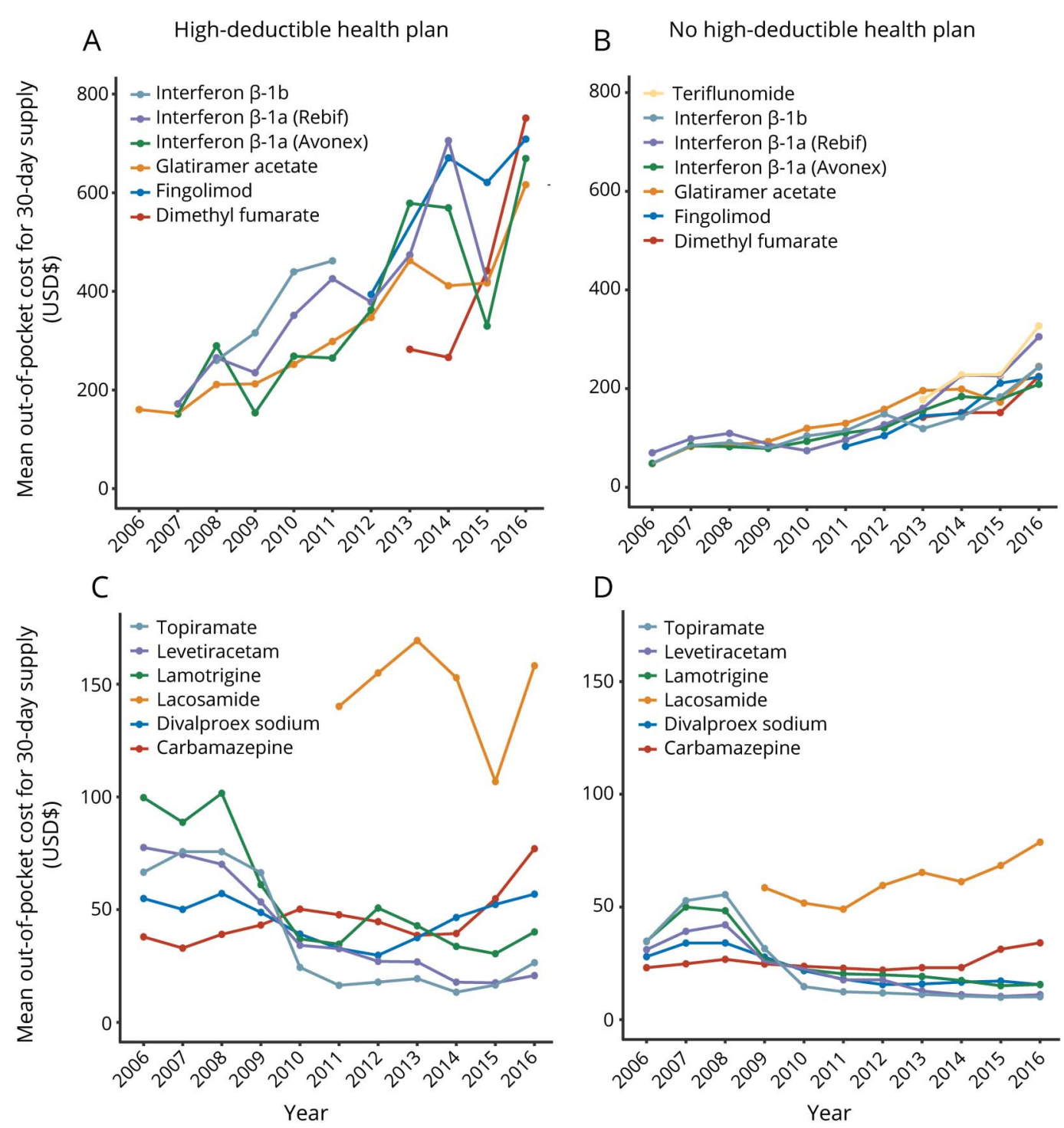

Monthly out-of-pocket costs (copay and deductible costs) for medications prescribed within 12 months of an outpatient visit to a neurologist for patients with multiple sclerosis (A, B) and epilepsy (C, D).

many years. However, from 2014 to 2016, out-of-pocket costs have started to represent a larger proportion of the total costs. Given new high-priced neurologic medications coming to the market and the rise in high-deductible health plans, it is likely that out-of-pocket costs will continue to increase and become even more important to neurologists and patients. Despite the increasing importance of these costs, neurologists and other physicians usually do not have knowledge of this information, ${ }^{12}$ particularly during office visits, despite physicians and patients recognizing the importance of discussing these costs. ${ }^{13}$ This prevents many patients and physicians from discussing medication alternatives based on a particular patient's disease, insurance plan, pharmacy, and current deductible. New information technology solutions are needed to allow these important conversations to occur. Furthermore, physician education should include training in how to discuss costs with patients and how to incorporate this information into shared decision-making.

Not only are out-of-pocket costs high and increasing, but they also vary considerably from patient to patient. Neurologists need to be aware that these costs can be different from 1 neurologic disease to another. For example, the mean $\mathrm{cu}-$ mulative out-of-pocket costs for patients with MS were 10fold higher than the costs for epilepsy patients $(\$ 2,238$ vs $\$ 230$ after 2 years). Therefore, patients with MS are more likely to want to discuss cost implications of their medications, and neurologists will need to be increasingly prepared for these conversations. Importantly, these costs also vary substantially for patients with the same condition. We found that 
Figure 3 Cumulative neurologic and non-neurologic out-of-pocket costs for patients with 2 common neurologic disorders over the first 2 years after diagnosis
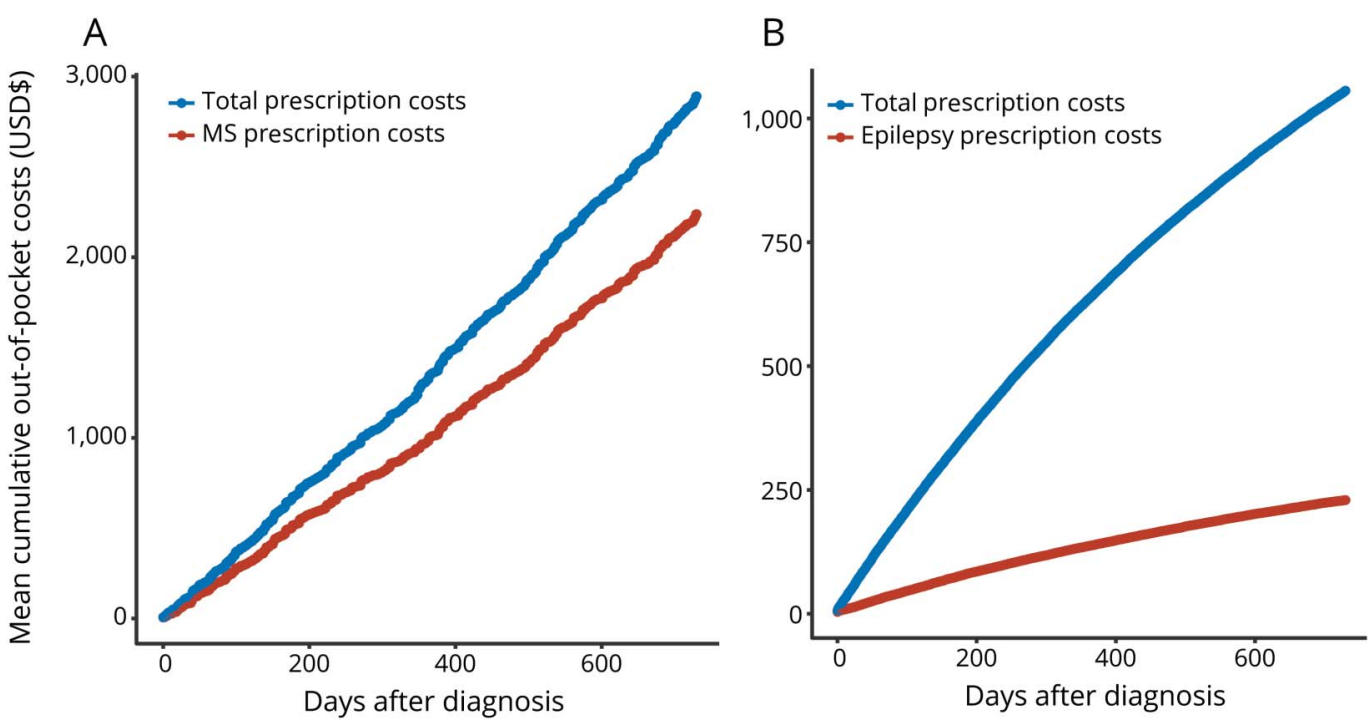

Cumulative neurologic and non-neurologic out-of-pocket costs (copay and deductible costs) for patients with multiple sclerosis (MS) (A) and epilepsy (B) over the 2 years after diagnosis in 2012 or 2013.

$5 \%$ of patients with MS pay $\$ 90$ or less over 2 years, but another $5 \%$ pay $\$ 9,855$ or more. Given that the median household income was \$53,039 in 2016 (census.gov), 5\% of patients with MS are spending more than $8 \%$ of the median household income on their medications each year. Patients in high-deductible health plans are particularly vulnerable to being a high outlier in regards to out-of-pocket costs since they are more likely to have a deductible payment in addition to a copayment for medications. As a result, neurologists cannot understand the costs implications to their patients just by knowing the condition that they have and the medication that they are prescribing. To know the precise cost implications for individual patients, neurologists would need detailed patient-specific information that is currently unavailable to most physicians. Currently, even well-informed neurologists will have trouble helping patients navigate their out-of-pocket expenses given the limitations in data available to them when making treatment decisions.

The difference in out-of-pocket costs for neurologic medications with similar indications and efficacy has implications for ideal prescribing behavior. For example, current evidence supports the use of gabapentinoids, serotonin and norepinephrine reuptake inhibitors, and TCAs for painful peripheral neuropathy. ${ }^{14-16}$ These medications likely have similar efficacy and tolerability. ${ }^{17}$ However, patient out-of-pocket costs are higher for pregabalin than for the other medications. ${ }^{18}$ Despite this cost difference, pregabalin is the second most commonly prescribed medication for this common condition after gabapentin. While most antiepileptic medications have similar and low out-of-pocket costs, lacosamide and other brand name epilepsy medications are expensive without evidence of higher efficacy or safety. ${ }^{19}$ Another example is the difference in out-of-pocket costs for donepezil compared to the more expensive galantamine and rivastigmine despite similar efficacy. ${ }^{20}$ Neurologists need to be aware of these differences in order to provide the best value of care to their patients.

Almost all physicians are aware that generic medications are less expensive than brand name medications. However, knowing the generic status of all medications is much more difficult. Furthermore, our data show that it usually takes years after a medication becomes generic before the total and outof-pocket costs drop to levels of comparable medications, and the time is also variable. For gabapentin, venlafaxine, ropinirole, and pramipexole, the drop in costs took approximately 5-6 years. For donepezil and multiple epilepsy medications, the drop took 2 years. The drop in medication costs is often delayed because it takes multiple companies making the generic version to drive enough competition to affect prices. While it is difficult enough for physicians to be aware whether all of the current medications they prescribe are available only as brand or have generic options, it is even harder to know whether enough time has passed for the cost differences to no longer be important. Given current electronic health record capability, this information should be readily available to patients and physicians. However, this would require insurance-based pharmacy benefit manager information to be accessible during electronic prescribing to show the potential out-of-pocket drug costs. A recent study showed that clinicians and prescribers frequently do not have the information they need to optimally prescribe based on health care coverage or formulary information. ${ }^{21}$ 
The highest change in out-of-pocket costs occurred for patients with MS. In 2016, patients were paying approximately $\$ 300$ per month in out-of-pocket expenses. For patients in high-deductible health plans, this cost doubles to about $\$ 600$ per month. Further study is warranted to determine if the higher out-of-pocket costs for patients with MS in high-deductible health plans result in lower treatment adherence and whether this affects clinical outcomes in this population. Previous studies have already shown that out-ofpocket costs, regardless of plan type, are associated with decreased adherence. ${ }^{8-10}$ Importantly, the out-of-pocket costs are almost identical for all of the MS medications, which is not surprising given previous data showing similar costs for these medications. ${ }^{22}$ The implication is that neurologists do not have a low-cost medication option for this patient population. While patient coupons may mitigate these costs, they also likely drive up insurance premiums. ${ }^{23}$ Though our data are from 1 large commercial insurer, in diseases such as MS, where a number of patients are Medicare beneficiaries, high prices without lower-priced options threaten to create a disproportionate spend of a fixed pool of resources that will limit care for other diseases. Solutions to the high cost burden to patients with MS would likely have to come at the level of reducing the total costs of these medications or at least 1 or more of these medications. Encouraging the development of biosimilars is one potential solution such as by allowing the first manufacturer time as the only competitor or by eliminating the requirement that companies disclose their process to the original manufacturer. ${ }^{24}$ Allowing negotiation of drug prices is another possibility to reduce these costs. ${ }^{1}$ Currently, the Veterans Affairs and other countries pay substantially less for MS medications, likely secondary to higher negotiating power. $^{22}$

Limitations include that the Clinformatics Datamart database only includes estimates by United Healthcare rather than actual total costs. In contrast, a strength of this database is that the out-of-pocket expenses are actual amounts and not estimates. No definitive linkage between provider type and medications or diagnostic tests was available; however, these costs are not likely to differ substantially based on which provider type ordered them. The data primarily focused on privately insured individuals from the largest private insurer in the United States. How these data generalize to other populations is unclear, for instance to older populations and those insured by Medicare and Medicaid. On the other hand, the study population is large, with similar demographics and regional distribution to the whole privately insured US population. Furthermore, we did not have data on how total annual dollars spent by patients compares in those in highdeductible plans compared to those in traditional plans. Our dataset did not include information from supplemental financial support programs such as from other insurers, pharmaceutical companies, or through philanthropic donations. Similarly, we do not have information on patients who tried but did not fill an initial prescription because of the out-ofpocket cost.
Over the last 12 years, out-of-pocket costs have transformed from being relatively unimportant to being extremely important. These costs vary substantially within and across neurologic conditions and even within the same medication. The trajectory of out-of-pocket costs in recent years suggests that these costs are likely to further increase, particularly as more expensive neurologic drugs become available and highdeductible health plans continue to increase. Neurologists should use out-of-pocket cost information to influence their prescribing practices, but first they must have this information available to them at the point of care.

\section{Author contributions}

Brian Callaghan and Jim Burke were involved in the study design, interpretation of the statistical analysis, and wrote the manuscript. Kevin Kerber, Lesli Skolarus, Brandon Magliocco, and Gregory Esper were integrally involved in interpretation of the data and critical revisions of the manuscript. E. Reynolds and M. Banerjee were involved in the statistical analyses, interpretation and presentation of the results, and critical revisions of the manuscript.

\section{Study funding}

The study was funded by the American Academy of Neurology Health Services Research Subcommittee. Dr. Callaghan is supported by a NIH K23 grant (NS079417) and a VA CSRD Merit (CX001504). Dr. Burke is supported by NINDS K08 NS082597 and R01 MD008879. Dr. Kerber is supported by NIH/NCRR K23 RR024009, AHRQ R18 HS017690, NIH/NIDCD R01DC012760, and AHRQ R18HS022258. Dr. Skolarus is supported by NIH/NIMHD R01 MD008879, NIH/NIMHD R01MD011516, and NIH/ NIMHD U01MD010579.

\section{Disclosure}

B. Callaghan receives research support from Impeto Medical Inc. He performs medical consultations for Advance Medical, consults for a PCORI grant, consults for the immune tolerance network, and performs medical legal consultations. E. Reynolds, M. Banerjee, and K. Kerber report no disclosures relevant to the manuscript. L. Skolarus has consulted for Bracket Global regarding poststroke disability. B. Magliocco reports no disclosures relevant to the manuscript. G. Esper performs medical legal consultations and also serves as a consultant for NeuroOne, Incorporated, an EEG device company. J. Burke has received compensation from Astra Zeneca for his role on the adjudication committee of the SOCRATES trial. Go to Neurology.org/N for full disclosures.

\section{Publication history}

Received by Neurology September 6, 2018. Accepted in final form January 8, 2019.

\section{References}

1. De Lott LB, Burke JF, Kerber KA, Skolarus LE, Callaghan BC. Medicare part D payments for neurologist-prescribed drugs. Neurology 2016;86:1491-1498.

2. Claxton G, Rae M, Long M, Damico A, Whitmore H, Foster G. Health benefits in 2016: family premiums Rose Modestly, and offer rates remained stable. Health Aff 2016;35:1908-1917. 
3. Banegas MP, Guy GP Jr, de Moor JS, et al. For working-age cancer survivors, medical debt and bankruptcy create financial hardships. Health Aff 2016;35:54-61.

4. Piette JD, Heisler M, Wagner TH. Problems paying out-of-pocket medication costs among older adults with diabetes. Diabetes Care 2004;27:384-391.

5. Hopson S, Saverno K, Liu LZ, et al. Impact of out-of-pocket costs on prescription fills among new initiators of biologic therapies for rheumatoid arthritis. J Manag Care Spec Pharm 2016;22:122-130.

6. Karter AJ, Parker MM, Solomon MD, et al. Effect of out-of-pocket cost on medication initiation, adherence, and persistence among patients with type 2 diabetes: the $\mathrm{Di}$ abetes Study of Northern California (DISTANCE). Health Serv Res 2018;53: $1227-1247$.

7. Hincapie AL, Penm J, Burns CF. Factors associated with patient preferences for disease-modifying therapies in multiple sclerosis. J Manag Care Spec Pharm 2017;23: $822-830$.

8. Dor A, Lage MJ, Tarrants ML, Castelli-Haley J. Cost sharing, benefit design, and adherence: the case of multiple sclerosis. Adv Health Econ Health Serv Res 2010;22:175-193.

9. Gleason PP, Starner CI, Gunderson BW, Schafer JA, Sarran HS. Association of prescription abandonment with cost share for high-cost specialty pharmacy medications. J Manag Care Pharm 2009;15:648-658.

10. Shao H, Stoecker C, Monnette AM, Shi L. Cost sharing of disease-modifying treatments (DMTs) as policy lever to improve DMTs' access in multiple sclerosis. Value Health 2018;21:1083-1089.

11. Quan H, Sundararajan V, Halfon P, et al. Coding algorithms for defining comorbidities in ICD-9-CM and ICD-10 administrative data. Med Care 2005;43: 1130-1139.

12. Shrank WH, Asch SM, Joseph GJ, et al. Physicians' perceived knowledge of and responsibility for managing patients' out-of-pocket costs for prescription drugs. Ann Pharmacother 2006;40:1534-1540.

13. Alexander GC, Casalino LP, Meltzer DO. Patient-physician communication about out-of-pocket costs. JAMA 2003;290:953-958.
14. Bril V, England J, Franklin GM, et al. Evidence-based guideline: treatment of painful diabetic neuropathy: report of the American Academy of Neurology, the American Association of Neuromuscular and Electrodiagnostic Medicine, and the American Academy of Physical Medicine and Rehabilitation. Neurology 2011;76:1758-1765.

15. Finnerup NB, Attal N, Haroutounian S, et al. Pharmacotherapy for neuropathic pain in adults: a systematic review and meta-analysis. Lancet Neurol 2015;14:162-173.

16. Griebeler ML, Morey-Vargas OL, Brito JP, et al. Pharmacologic interventions for painful diabetic neuropathy: an umbrella systematic review and comparative effectiveness network meta-analysis. Ann Intern Med 2014;161:639-649.

17. Finnerup NB, Sindrup SH, Jensen TS. The evidence for pharmacological treatment of neuropathic pain. Pain 2010;150:573-581.

18. Callaghan BC, Feldman EL. Painful diabetic neuropathy: many similarly effective therapies with widely dissimilar costs. Ann Intern Med 2014;161:674-675.

19. Hu Q, Zhang F, Teng W, et al. Efficacy and safety of antiepileptic drugs for refractory partial-onset epilepsy: a network meta-analysis. J Neurol 2018;265:1-11.

20. Raina $P$, Santaguida $P$, Ismaila A, et al. Effectiveness of cholinesterase inhibitors and memantine for treating dementia: evidence review for a clinical practice guideline. Ann Intern Med 2008;148:379-397.

21. DeMuro PR, Ash J, Middleton B, Fletcher J, Madison CJ. A quality, benefit, cost, and financial framework for health information technology, E-prescribing: a Delphi study. Stud Health Technol Inform 2017;241:69-75.

22. Hartung DM, Bourdette DN, Ahmed SM, Whitham RH. The cost of multiple sclerosis drugs in the US and the pharmaceutical industry: too big to fail? Neurology 2015;84:2185-2192.

23. Starner CI, Alexander GC, Bowen K, Qiu Y, Wickersham PJ, Gleason PP. Specialty drug coupons lower out-of-pocket costs and may improve adherence at the risk of increasing premiums. Health Aff 2014;33:1761-1769.

24. Falit BP, Singh SC, Brennan TA. Biosimilar competition in the United States: statutory incentives, payers, and pharmacy benefit managers. Health Aff 2015;34: 294-301. 